Fourth International Conference on Sustainable Construction Materials and Technologies http://www.claisse.info/Proceedings.htm

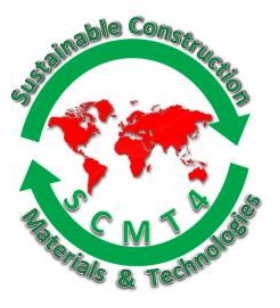

SCMT4

Las Vegas, USA, August 7-11, 2016

\title{
Overview on Biobased Building Material Made with Plant Aggregate
}

\begin{abstract}
Sofiane Amziane ${ }^{1}$
${ }^{1}$ Institut Pascal, UMR 6602, Clermont University, Clermont Ferrand, France, Email: <sofiane.amziane@univ-bpclermont.fr>

ABSTRACT

Using plant material as raw materials for construction is a relatively recent and original topic of research. This paper presents an overview of the current knowledge on the material properties and environmental impact of construction materials made from plant particles, which are renewable, recyclable and easily available. It focuses on particles and as well on fibers issued from hemp plant, as well as discussing hemp concretes. The paper begins by setting the environmental, economic and social context of agro-concretes, before discussing the nature of plant-based aggregates and binders. The formulation, implementation and mechanical behavior of such building materials are the subject of the following parts. The focus is then put upon the hygrothermal behavior and acoustical properties of hempcrete, followed by the use of plantbased concretes in structures. The paper concludes with the study of life-cycle analysis (LCA) of the environmental characteristics of a banked hempcrete wall on a wooden skeleton.
\end{abstract}

\section{INTRODUCTION}

Environmental, economic and social context of agro-concretes. The concept of sustainable development dealt with locally is often linked to problems on a worldwide scale, such as global warming or the gradual exhaustion of resources. These two criteria constitute the points of no return for our civilization.

As regards the climate, the scientific works of the IPCC serve as a referential framework. The second assessment report (SAR) published by this organization in 1995 concludes that the "the balance of evidence suggests a discernible human influence on global climate". A mere two years later, on the basis of this report and the UN Framework Convention on Climate Change, the international political debates culminated in the Kyoto Protocol. This text commits the countries which have ratified it to reduce their GHG emissions by 5.2\% in comparison to their level in 1990 over the period 2008-2012. The protocol came into force in 2005 and therefore will conclude in 2012. Owing to its use of nuclear and hydroelectric energy, which do not produce much Green House Gaz (GHG), France is committed to maintaining these levels of emissions. A greenhouse gas (sometimes abbreviated GHG) is a gas in an atmosphere that absorbs and emits radiation within the thermal infrared range. This process is the fundamental cause of the greenhouse effect. 
For its part, the construction sector (residential and tertiary), much like the agricultural or industrial sectors, finds itself facing significant challenges in terms of reducing GHG emissions and energy consumption. The figures speak for themselves, but they must be analyzed seriously. Indeed, it is not always entirely clear what data have been taken into account when producing the figures, particularly in terms of drawing the distinction between a building's function and its construction:

Total GHG emissions from both energetic and non-energetic sources (e.g. agriculture, forestry, etc.): 7.9\% on a global scale, $40 \%$ on the scale of the US and $18 \%$ on the scale of France in 2007 for all residential/tertiary, institutional and commercial consumption (heating, specific electricity, hot water, cooking, etc.),

Final electrical energy consumption: $41 \%$ on the scale of the US in 2010 and $43.4 \%$ on the scale of France in 2008 for all residential/tertiary, institutional and commercial use. These figures do not include the fossil energy required to produce the electricity.

However, while climate change represents an alarming phenomenon, it is not the only point that needs to be taken into account. The natural resources needed for the perpetuation of human activities and societies are, for the most part, finite and exhaustible. Similarly to the threat of global warming, exhaustion of resources - be they minerals or arable land - is a major point of doubt which will inevitably lead us to change our ways before the current century is out. The activities relating to construction and to public projects, while they do not necessarily require materials to be used which come from exhaustible sources (with the exception of road infrastructures, which consume bitumen), constitute the single greatest cause of consumption of natural resources (31\% in Europe). Furthermore, this consumption causes a large amount of waste production, even though $97 \%$ of the waste produced by construction and public works in France are inert and are subject to a policy of value-creation. In France, the amount of waste generated by this domain equaled 343 million tons in $2004,44 \%$ of the total mass.

In summary, the construction sector battles four main impacts on the environment:

- Its GHG emissions;

- Its energy consumption;

- Its consumption of natural resources;

- Its waste production

\section{Role of the materials in energy consumption}

The distribution of the energy consumption between the heating post and that devoted to the materials and construction of a conventional house (see Figure 1.) reveals the greater relative weight that this second post as the building plan is gradually applied. Indeed, we see a rise from $8 \%$ to $60 \%$ in the relative proportion of the materials and the construction in the energy consumption for a building with a lifespan of 100 years, while the consumption from heating plummets from $200 \mathrm{kWh} / \mathrm{m}^{2} / \mathrm{yr}$ to $15 \mathrm{kWh} / \mathrm{m}^{2} / \mathrm{yr}$ (RT 2012).

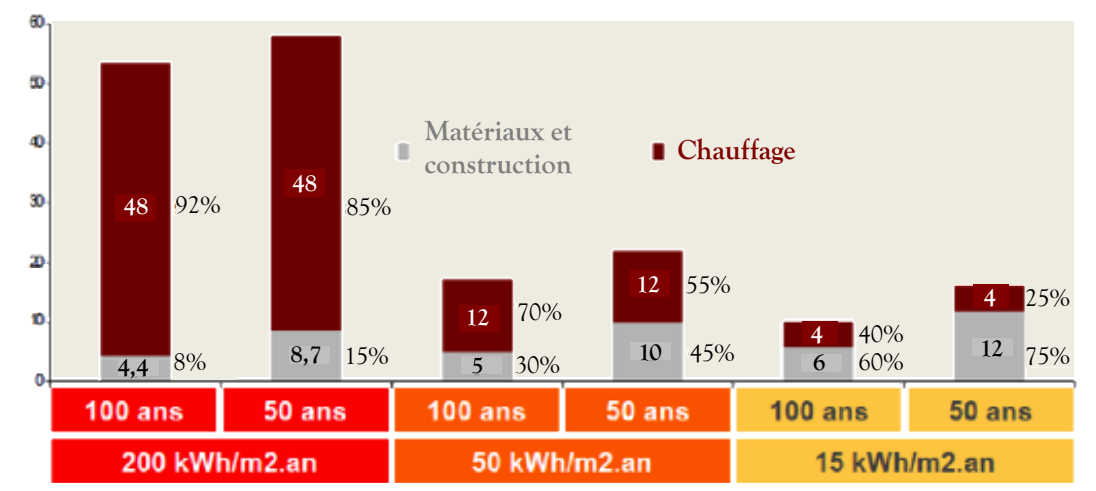

Figure 1. Distribution of the energy consumption of buildings, due to heating and to materials and construction respectively. 
In addition, the durability of the construction material used is also of crucial importance. If the lifespan drops from 100 to 50 years for a building that consumes $15 \mathrm{kWh} / \mathrm{m}^{2} / \mathrm{yr}$, the relative proportion of the materials and construction in the building's energy consumption jumps from 60 to $75 \%$. Thus, we can understand the important issues which will affect the construction materials market in a not-too-distant future, be it in terms of new construction or renovation of old buildings.

Development of agro-concretes in the context of France. It is certain that with the now-omnipresent "sustainable development", the use of so-called renewable materials (if they are managed correctly) and local materials presents a growing advantage in the world of construction materials, in France and in the rest of the world. Around the main markets generated by a cereal or petroleum culture, there are a great many secondary markets springing up, which will facilitate as complete a value creation as possible. Such is the case, in particular, for hemp, for which the corners of the market are as varied as the automobile industry for the fibers, foodstuffs for the grain or indeed the wood of the stem for construction. The quantities and the sources available are abundant. Hence, vegetable biomass has a bright future.

What does the term "Agro-concrete" mean? A concrete in the conventional sense of the word consists of a heterogeneous mix between a mineral binder and granulates (also mineral in origin) of graduated dimensions [2]. Similarly, that which we define as Agro-concrete will therefore consist of:

"A mix between granulates from lignocellular plant matter coming directly or indirectly from agriculture or forestry, which form the bulk of the volume, and a mineral binder".

This definition will not cover mixtures including:

- a low proportion of lignocellular granulates;

- lignocellular plant fibers to reinforce conventional concrete.

Table 1. Overview of research into materials mixing mineral binders and lignocellular products for the making of lightweight concretes

\begin{tabular}{|c|c|c|c|c|}
\hline Plant & Valuable material & Source(s) & Binder(s) used & Countries \\
\hline \multirow{2}{*}{ Hemp } & \multirow{2}{*}{ Hemp wood } & \multirow{2}{*}{$\begin{array}{l}\text { Agricultural co- } \\
\text { product }\end{array}$} & \multirow{2}{*}{$\begin{array}{l}\text { Tradical@ PF70, } \\
\text { hydraulic lime, } \\
\text { methacholine/lim } \\
\text { e mix }\end{array}$} & France \\
\hline & & & & Elsewhere \\
\hline Flax & Shive, tow & $\begin{array}{c}\text { Agricultural co- } \\
\text { product }\end{array}$ & $\begin{array}{l}\text { Portland cement, } \\
\text { Cement + Sucrose }\end{array}$ & France \\
\hline \multirow{2}{*}{ Wood (all types) } & \multirow{2}{*}{$\begin{array}{l}\text { Sawdust, } \\
\text { shavings }\end{array}$} & \multirow{2}{*}{ Sawmill waste } & $\begin{array}{l}\text { Portland cement, } \\
\text { Cement/clay mix }\end{array}$ & France \\
\hline & & & Portland cement & Elsewhere \\
\hline Sunflower & Stem & $\begin{array}{c}\text { Agricultural by- } \\
\text { product }\end{array}$ & $\begin{array}{l}\text { Methacholine/lim } \\
\text { e mix }\end{array}$ & France \\
\hline Beetroot & $\begin{array}{l}\text { Dried beetroot } \\
\text { pulp }\end{array}$ & $\begin{array}{l}\text { Food industry } \\
\text { waste }\end{array}$ & Portland cement & France \\
\hline Coconut & Shell & $\begin{array}{l}\text { Food industry } \\
\text { waste }\end{array}$ & Portland cement & Elsewhere \\
\hline Durian & Shell & $\begin{array}{l}\text { Food industry } \\
\text { waste }\end{array}$ & Portland cement & Elsewhere \\
\hline Cork & Wood & Industrial waste & Portland cement & Elsewhere \\
\hline Miscanthus & Stem & $\begin{array}{l}\text { Co-product } \\
\text { (ethanol) }\end{array}$ & Portland cement & France \\
\hline
\end{tabular}


Indeed, many projects aim to create construction materials using one or more forms of lignocellular matter as a reinforcement to the structure rather than as a lightweight aggregate with an insulating purpose. The materials used are generally fibers which serve to improve the traction resistance, ductility and postfracture behavior of composite concretes made in this way. The scientific study of Fiber-Reinforced Concrete (FRC) created from mineral or synthetic fibers began at the start of the 20th Century. More recently, projects have been carried out to enhance the value of organic fibers to substitute industrial fibers. They are drawn from various sources, such as wood, coconut, sisal, palm, bamboo, bagasse or indeed diss. It is interesting to note that countries such as Brazil which have an exceptional range of flora have a wide range of fibers to experiment with, and research in this domain is very active.

All these resources (table 1) have a common point: they are either co-products or by-products, or industrial waste. This is not an exhaustive list, because industrial projects are conducted with other plant matter such as miscanthus or wheat straw. These materials, readily and cheaply available, therefore logically hold a growing interest for many uses - particularly for creating agro-concretes. Their increasing value also facilitates a reduction of the environmental impacts as opposed to traditional building insulation systems. Indeed, these materials are renewable, biodegradable, neutral in terms of GHG emissions and require little energy to be transformed. However, not all of them can be used, and it is necessary to define a set of specifications to guide their selection.

Properties of plant aggregate. Bio-based aggregate are coming from the stem of plants cultivated either for their fibers (hemp, flax, etc.) or for their seeds (oleaginous flax, sunflower, etc.). Owing to the structure of the stem of the plant they are made from, such aggregates are generally malleable, elongated and highly porous with a low apparent density. They are very different from the mineral aggregates typically used in concretes, for which there are standardised tools and techniques for characterisation. Amongst these, hemp shiv (the woody core of the stem of the hemp plant) is probably the most widely used in alternative or eco-friendly building materials in Europe and is also representative of most of the aggregate coming from the stem of an annual crop (Figure 2). This is usually mixed with a lime-based binder and the resultant 'bio-concrete' is known as 'hemp-lime'.

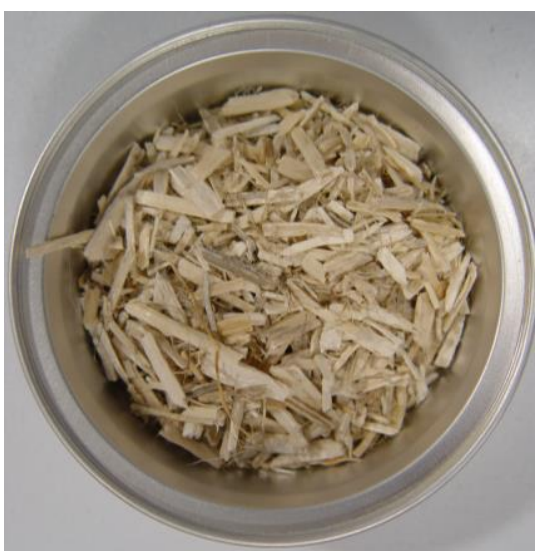

Figure 2. Hemp shiv

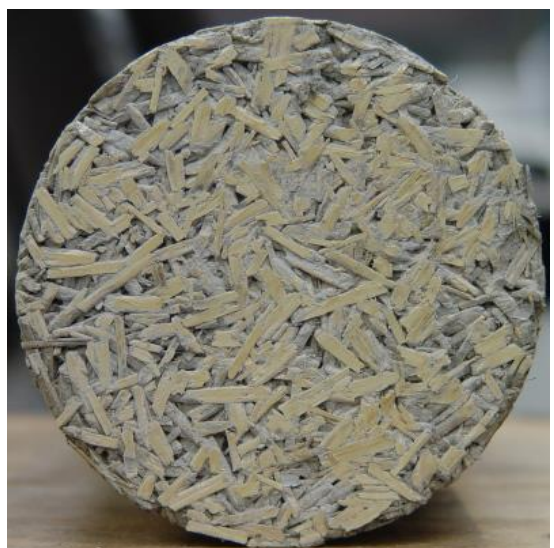

Figure 3. Hempcrete

This kind of aggregate is a co-product of hemp industry that is renewable and produced in an annual cycle while the price of mineral aggregates is steadily increasing as resources become less readily available. The characterisation of these aggregates, however, which is crucial to a proper understanding of the quality of the materials in which they are incorporated, requires adaptations to be made to the techniques usually employed for mineral aggregates, or the devising of new characterisation procedures. 
A round robin test of the Rilem TC-BBM was carried out to compare the protocols in use by the different labs. The aim was to define a test method to measure initial water content and water absorption of bio aggregates. This round robin test was carried out with one variety of hemp shiv (the woody core of the plant stalk chopped into lengths of a few centimeters) coming from the same production of a processing factory located in France. As with other lignocellulosic materials, hemp shiv is known to present a high hygroscopic behaviour. The water content of hemp shiv will then be largely influenced by relative humidity of air at the time of bagging or mixing. This property needs to be assessed as it can strongly influence the mix proportioning of hemp-lime and consequently the properties of hardened hemp-lime.

The hygroscopic behavior of lignocellulosic plants is largely due to their hydrophilicity. Their complex architecture is marked by a multi-scale porosity in order to conduct the necessary fluids for their development (sap and water). Even after cutting and processing, this porosity continues to play its role and is therefore the main way of absorption of water folloowing the Laplace laws. This absorption occurs mainly by conducting vessels or tracheids before the water spreads to the rest of the cells by diffusion through the cell walls and punctuation. The typical value of absorption is about $350 \%$.

The bulk density of hemp shiv is linked to the porosity of the particles and to the inter-particular porosity. The bulk density of hemp shiv is measured in a cylindrical mould with a loose packing and without compaction. The typical value obtained is about $100 \mathrm{~kg} / \mathrm{m}^{3}$.

The particle size distribution of bio-aggregate may be studied from sieving method and/or from image analysis [3].

Binders. Various binders may be used to make construction materials based on granulates and fibers of plant origin. The choice is essentially made on the basis of the main properties sought (mechanical properties, thermal properties, etc.), which will depend on the usage to be made of the material (support, insulation, etc.), on its manufacture (prefabricated in a factory, poured on site, projected ("shotcrete"), etc.) and on its location in the construction (indoors, outdoors, sheltered or otherwise). The choice may also be guided by financial considerations (e.g. local prices of materials) and environmental factors (CO2 balance, for instance). Among the most commonly used materials, we find Portland cements and hydraulic or aerated lime, most often associated with pozzolanic additives such as fly ash, blast furnace slag and metakaolin. We also find plaster for applications where it is sheltered from humidity. Certain commercial binders developed specifically for hemp concrete (hempcrete) are also obtained by mixing these different compounds: for instance, $70 \%$ slaked lime, $15 \%$ hydraulic lime and $15 \%$ pozzolana [ESC 13].

Hempcrete. Often, professionals have used experimentation (trial and error) to define the proportions of the various components needed to ensure the criteria of fluidity necessary for the installation, depending on the application for which the hempcrete is intended (Figure 3). This section brings together various formulation data put forward by the suppliers of binder or communicated by the construction experts who apply the products. As we saw previously, the formulations proposed are given for a particular type of binder - usually pre-formulated.

Finally, these typical formulations are not an absolute guarantee that the mechanical criteria of the hardened hempcrete will be fulfilled [LAN 13].

Table 2. Examples of mix proportioning: walling application

\begin{tabular}{|l|l|l|l|}
\hline Binder type & Hemp (liters) & binder (kg) & water (kg) \\
\hline Tradical PF 70 (CBC) & 100 & 22 & $30-35$ \\
\hline Prompt natural cement (Vicat) & 100 & 25 & $24-30$ \\
\hline Socli or Rabot lime (Socli) & 100 & 35 & $40-44$ \\
\hline $\begin{array}{l}\text { Bâtichanvre [Buildhemp] } \\
\text { (St. Astier) }\end{array}$ & 100 & $25-35$ & $35-40$ \\
\hline
\end{tabular}


Table 3. Examples of mix proportioning: Roofing application

\begin{tabular}{|l|l|l|l|}
\hline Type of binder (manufacturer) & Hemp (liters) & binder $(\mathrm{kg})$ & water $(\mathrm{kg})$ \\
\hline Tradical PF 70 (CBC) & 100 & 11 & $20-25$ \\
\hline Prompt natural cement (Vicat) & 100 & 12.5 & 22 \\
\hline $\begin{array}{l}\text { Socli or Rabot lime or Renocal } \\
\text { (Socli) }\end{array}$ & 100 & 17.5 & $17.5-20$ \\
\hline Bâtichanvre (St. Astier) & 100 & $12.5-17.5$ & $17.5-20$ \\
\hline
\end{tabular}

\section{Multiphysical Properties of Hempcrete}

Hempcrete is a mixture, in very changeable proportions, of two very different components: a plant-based granulate and a hydraulic and aerated setting binder. It exhibits multiphysical behavior which is unusual in the domain of construction materials. Indeed, the particles of hemp wood are characterized by a high degree of porosity which results in a high capacity to deform, absorb sounds and have hygrothermal transfer ability: this is one of the essential characteristics which set hempcretes apart from tradition mineral-based concretes for which the granulates are considered non-deformable. This difference has major effects on the performances of these concretes in all areas - acoustic, thermal, etc. - and of course, it has a direct impact on the mechanical properties of these innovative concretes. The aim of this part is to show why and how these concretes are distinguished from conventional concretes, and in particular to establish the properties of use and the characteristic values necessary for their use in construction.

Mechanical properties. As a mixture of plant particles and binder, hempcrete is an unusual construction material: the high flexibility of the granulates in conjunction with the rigidity of the cement matrix leads to a non-fragile elasto-plastic behavior. Thus, it is distinguished from other construction materials by a high deformability under stress, lack of fracturing and marked ductility with absorbance of the strains ever after having reached the maximum mechanical strength.

It is also helpful to highlight another peculiarity: the variability of the behavior depending on the formulation enables us to adjust and optimize the performances of this material for diverse applications as a roof filling material, in walling or as flagging (Figure 4). Depending on the concentration of binder, three types of behaviors of hempcrete are observed. For small doses of binder, we have a material with poor mechanical strength and an elasticity modulus of less than 5MPa. The levels of deformation are very high (>15\%). This material behaves like a sample of loose particles with "bridges of binder" connecting them. It is pre-destined for applications where thermal or acoustic insulation is important. For intermediary doses, the level of performance increases with the quantity of binder. The behavior of the material becomes progressively more similar to that of materials with large doses of binder. The binder matrix guides the behavior. For large doses of binder, the material is comparable to a continuous binder matrix in which the plant particles are buried. The mechanical performances increase and tend towards those of the pure binder. However, the high deformations that this concrete is capable of dealing with make it advantageous as a filling material. It can undergo differential compression, contract or dilate with no apparent cracking.

The mechanical strengths and the elasticity moduli obtained during the course of this experimental work are poor in comparison to other lightweight concretes such as wood-based concretes of cellular concrete. Thus, at present, it appears crucial to use load-bearing structures to support these concretes. However, compacting and therefore rearranging plant particles with anisotropic properties seems to be one way of using them differently. It seems interesting to apply stress to them in the direction perpendicular to their compaction, i.e. the direction in which their rigidity is greatest. However, this implies increasing the shear stress at the particle/matrix interface, which at present is still a weak point of the material. 


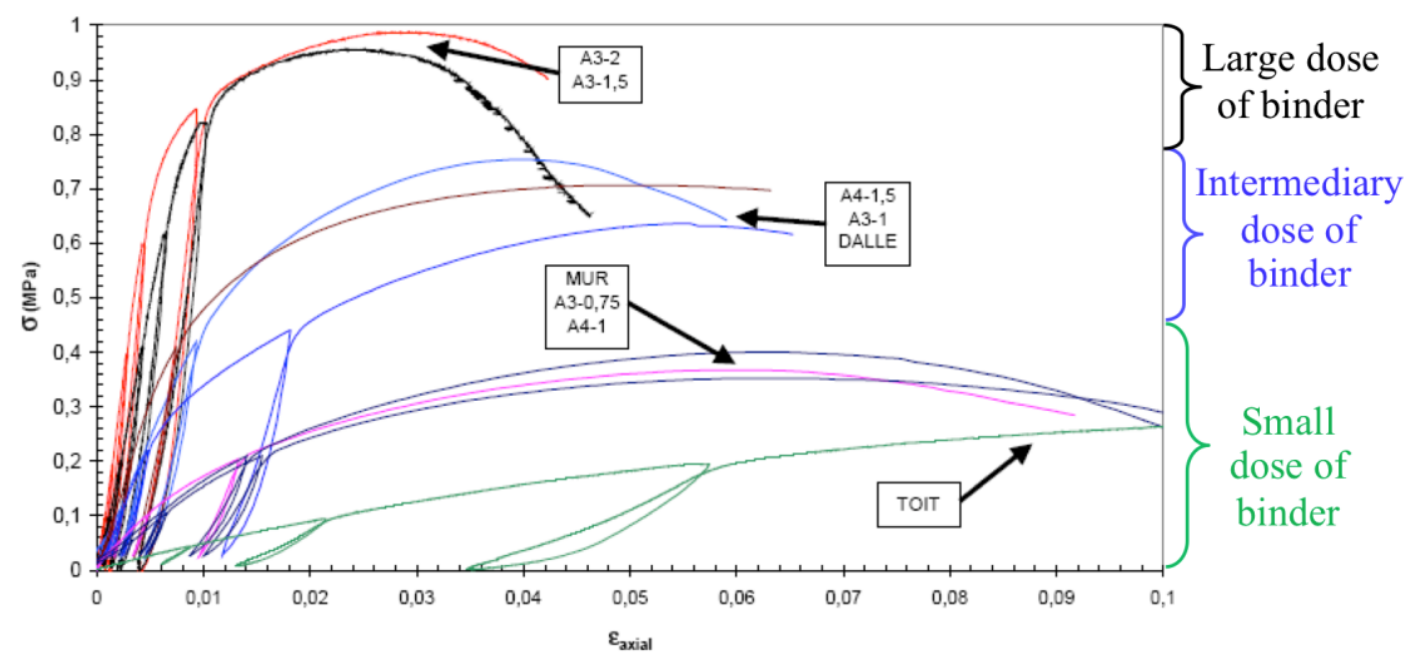

Figure 4. Influence of the dose of binder on the compressive strength of the hempcrete shaped by compaction (0.05MPa) after 1 year of setting [ARN 13]

Hygrothermal properties. The building of dwellings or renovation work including hemp-based materials often draw initial comments from users that are very positive in regard to the thermal and hygrothermal conditions.

The particular reasons behind this fact are the physical characteristics of these materials - their high porosity (between $70 \%$ and $80 \%$ ) - meaning they all have excellent insulating properties [ARN 13].

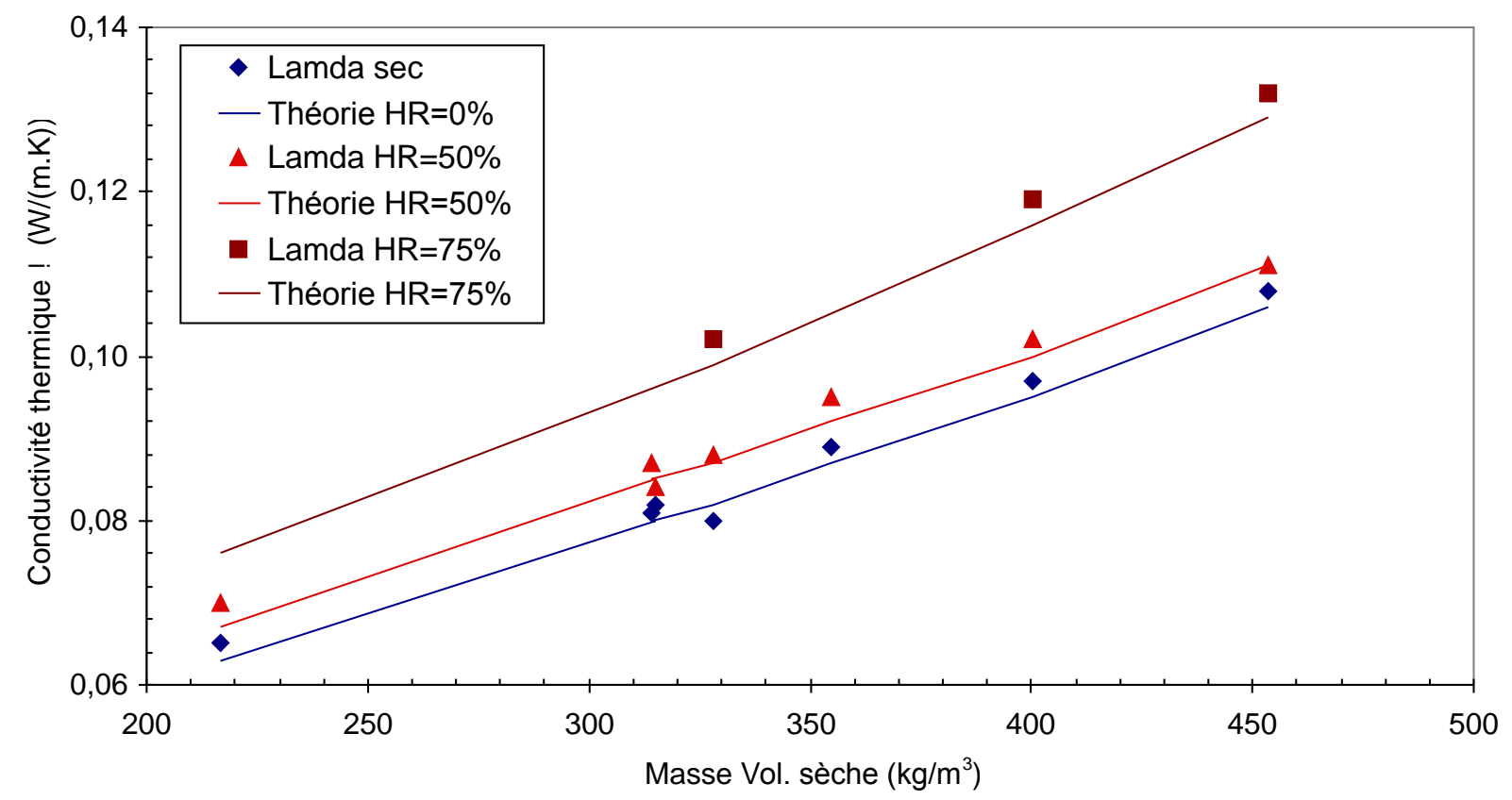

Figure 5. Evolution of the heat conductivity of hempcrete depending on the density and under different conditions of relative humidity 


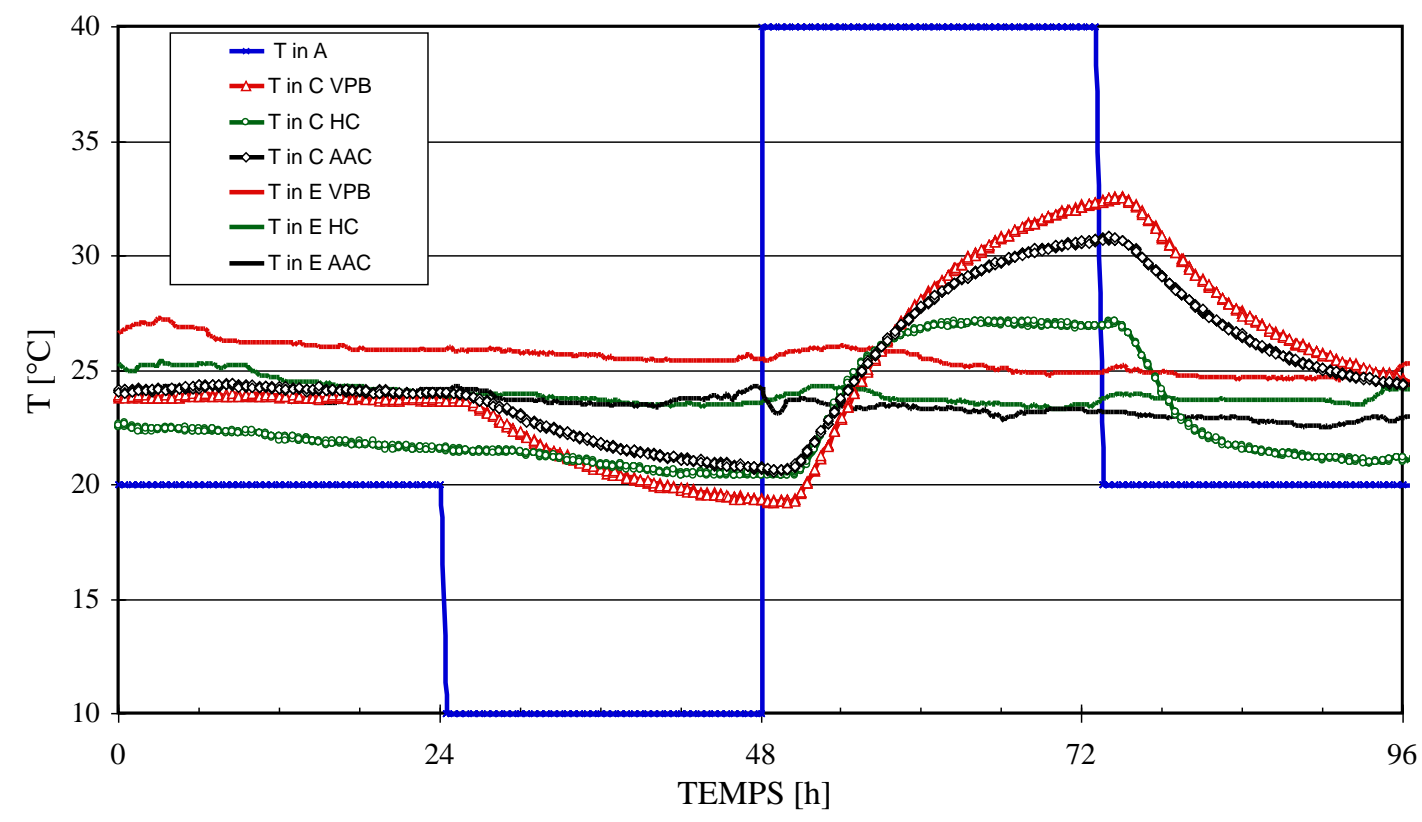

Figure 5. Response at different temperature platforms: comparison of walls made of autoclaved aerated concrete (AAC), vertically perforated bricks (VPB, made of fired earth) and hempcrete (HC). The solid lines represent the change in the temperature of the laboratory, considered to be constant.

Hemp-based materials naturally behave as also phase-change materials (PCM) (Figures 5 and 6): the thermal behavior reduces the amplitude of the variations in the ambient air temperature, whilst improving the thermal comfort by bringing down the surface heat of the material. Thus, the use of such materials is an excellent means of passively regulating the indoor temperature, and thereby decreasing the building's energy requirements. In addition, the experimental results show a regulation of the relative humidity in the envelope because of constant exchanges of water vapor between the indoor and outdoor environments, modulating sudden changes in temperature. Hence, these materials are able to improve summer and winter comfort, and stabilize the indoor temperature between day and night, whilst preventing the phenomena of condensation and dampness on the walls.

Work is currently being done with a view to integrating this model of hygrothermic behavior into the computation software used to predict the energy performances of buildings. It should be stressed that such projections are required by the thermal regulations currently in force (in France, RT 2005 and now RT 2012). It is therefore urgent to react because to date, none of these software tools takes account of the genuine dynamic hygrothermic behavior of the building materials and, as demonstrated in this chapter, this leads to a significant under-estimation of the actual performances of hemp-based materials. Therefore, these under-appreciated, high-performance solutions are often disregarded - and wrongly so!

Acoustic properties. Hempcrete is a material whose acoustic properties can vary greatly depending on the properties of its components and the way in which it is put to use (Figure 7, [GLE 13]). In particular, the results presented herein highlight that the parameters of installation have a far stronger influence than the properties of the components, with the apparent density of the material and the binder-to-shiv mass ratio playing an important part. Thus, by combining these different parameters, it is possible to find the optimal formulation of a hempcrete for any given application. 


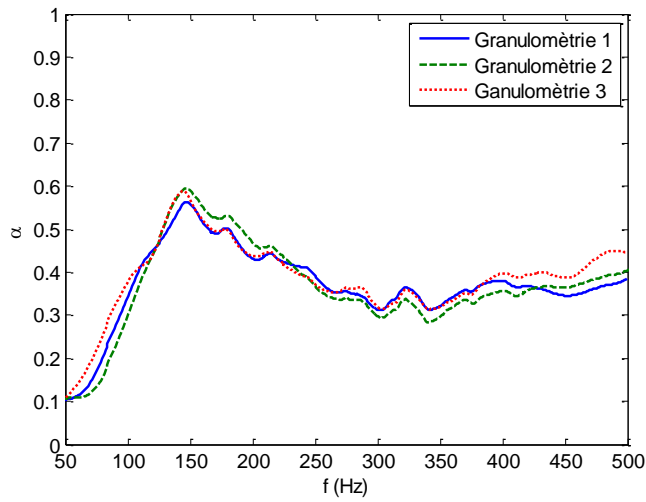

\section{Figure 7. Sound absorption of hempcretes depending on the PSD - walling formula with hydraulic lime}

Hempcrete in a wooden structure. A test bank was designed and built in order to carry out a full-scale bracing test on a panel with a wooden skeleton braced by struts (Figure 9, [MUN 13]). Apart from the flat positioning of the panel, in many ways it is in line with a norm currently in force.

A second test on a wooden panel - not braced this time, but rather filled with banked hempcrete - was then carried out.

The results, when analyzed, demonstrated that the presence of the hempcrete as a filler of the panel is able not only to substitute the bracing struts (which, incidentally, are the pieces which require most work when the skeleton of the panel is being built), but also to greatly improve the mechanical behavior in terms of bracing. Indeed, the peak charge is 2.2 times higher, but in particular, the bracing rigidity is increased almost tenfold.

Remember that in the two tests, the wooden skeleton of the panels was rigorously made identical apart from the presence of the bracing struts.

Finally, the hempcrete provides a degree of ductility which is advantageous as the point of rupture approaches, in that it limits any risk of instability at the level of the elements of the wooden skeleton (Figure 10).

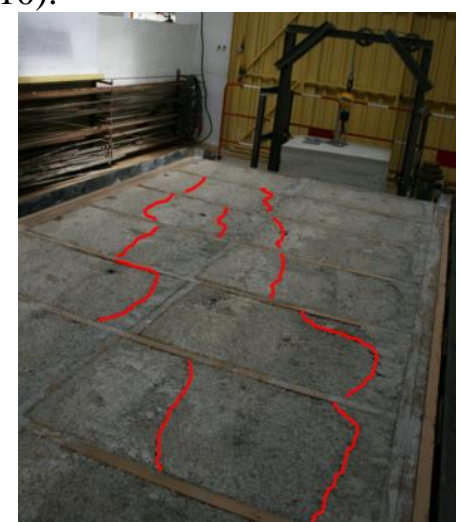

Figure 9. Cracking of the hempcrete at the end of the test (photo taken from the point of horizontal loading)

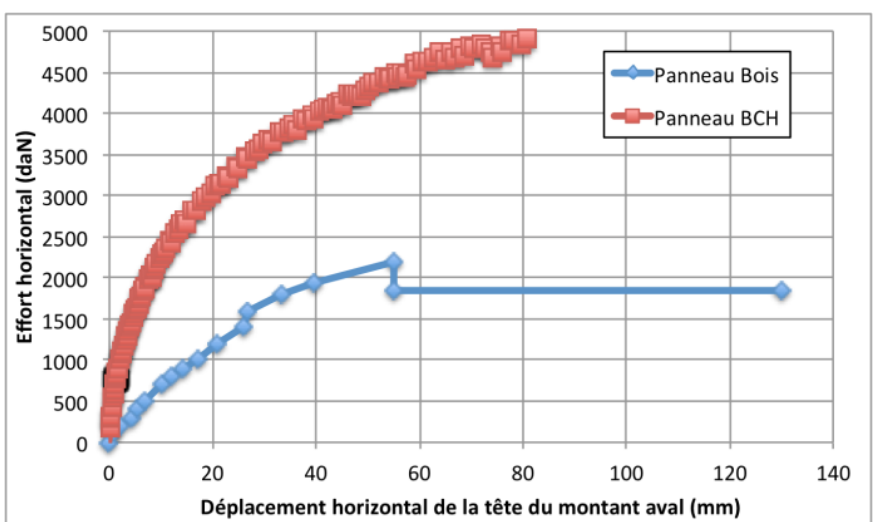

Figure 10. Bracing behavior of the "braced wood" and "hempcrete-filled" panels

Let us point out that since these tests were carried out, we have continued to make alterations to the testing bank to be used, replacing the strain application system and the sensors in order to integrate them into an acquisition and control system whereby the test can be conducted more rigorously. 
While these tests still need to be repeated on a greater number of test substances in order to confirm these trends, and a statistical analysis of the measurements recorded needs to be carried out, we can conclude that the development of a computation model that is able to take account of the contribution of hempcrete in absorbing the strain in bracing seems to present real potential.

This approach should enable us to optimize or simplify the panels with wooden skeletons in order to enhance the economic relevance of the construction system.

Life Cycle Analysis of Hempcrete. According to the study published by Boutin et al. [BOU 13] there is a favorable impact on the greenhouse effect; the hempcrete wall constitutes an interesting carbon absorber for a duration of at least 100 years, because it stores more $\mathrm{CO} 2$ in its three carbon absorbers -i.e. the hemp shiv, the wood and the Tradical ${ }^{\circledR}$ (lime) - than is emitted by its life-cycle (net balance of $35 \mathrm{~kg} \mathrm{CO} 2$ eq. stored over 100 years per $\mathrm{m} 2$ of hempcrete wall). In time, the $\mathrm{CO} 2$ stored in the organic parts of the wall will be restored to the atmosphere (Figures 11 and 12).

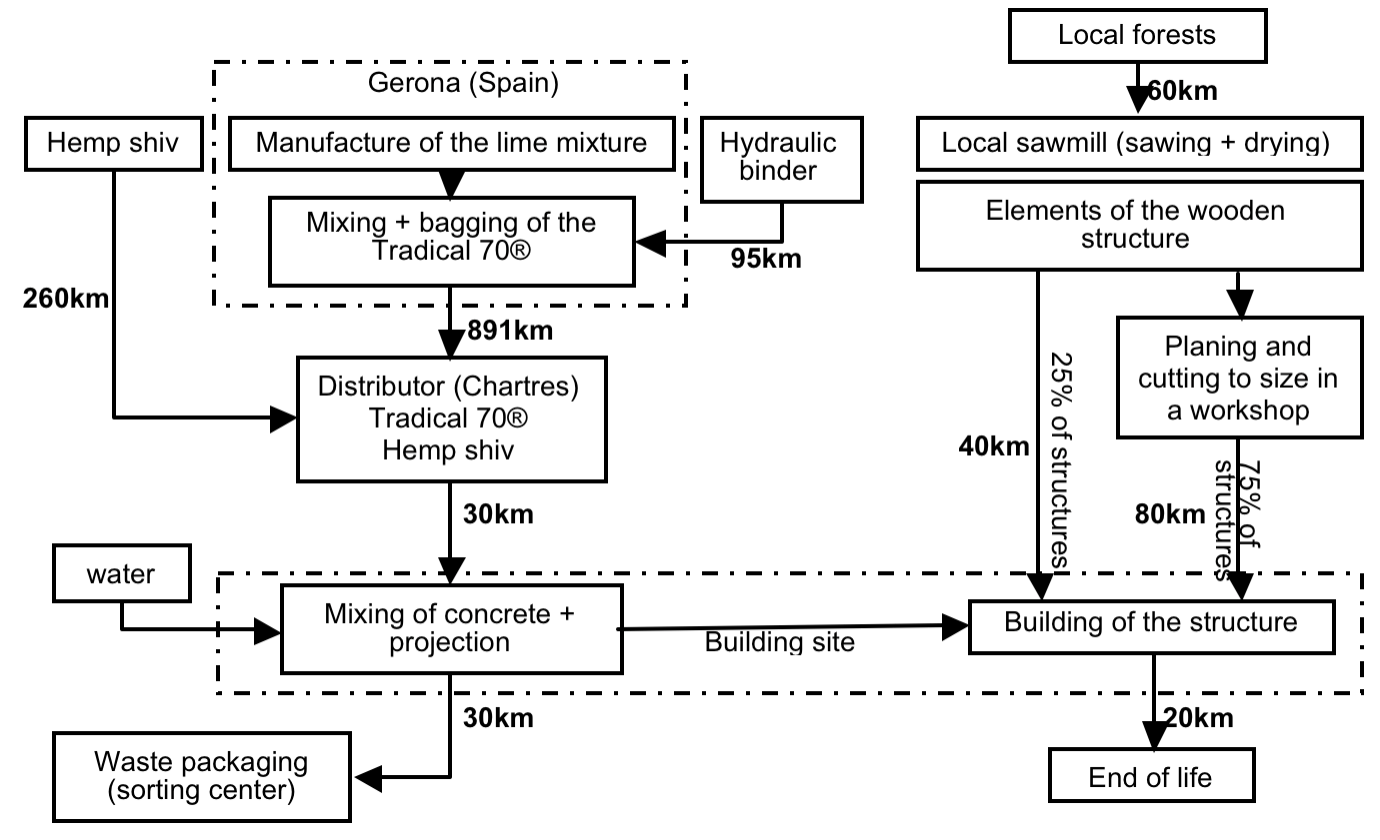

Figure 11. Reference scenario for a life-cycle analysis on a banked hempcrete wall on a wooden skeleton (Source: BCB-Lhoist, Construire en chanvre)

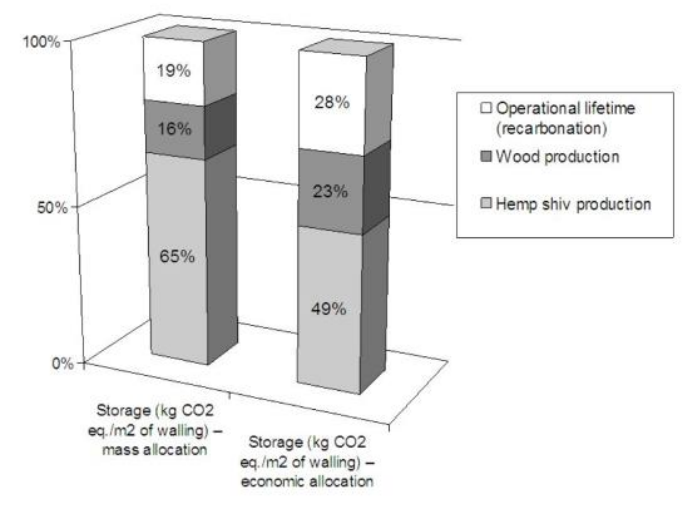

Figure 12. Distribution of the storage of $\mathrm{CO} 2$ between the three carbon absorbers in the banked hempcrete wall on a wooden skeleton 


\section{CONCLUSION}

The conclusion of this paper is well summarized by Prof. Henri Vandamne who writes the foreword of reference [AMZ 13] ......"Contrary to popular opinion, sand and other granular (particulate) minerals are not an inexha ustible resource. Unless we wish to inflict irreparable damage on the environment, the time has come for recycling, or for using bio-sourced particulates, which is essentially the same thing. This is the path adopted by agro-concretes and, in particular, hemp concretes. France is the largest producer in Europe of Cannabis Sativa, whose fibers have been used to make rope for centuries. Yet this fast-growing plant, well adapted to temperate climates, harbors many other resources. Its stem, of a highly porous and therefore very lightweight wood, when ground up makes a surprising granulate. Surprising, not on a mechanical level - the only level which truly counts for mineral granulates, with cleanliness and shape in joint second place - but surprising, primarily, on a functional level: the level of hygrothermal equilibrium and acoustic properties.

Looking at the proliferation of synthetic materials available on the market, one might think that thermal, hydral and acoustic comfort is a domain in which the materials available - particularly when these materials are used in combination - have nearly reached the optimum desired. Polymer foams and organic and inorganic aerogels have extremely low thermal diffusivity and air permeability, which are difficult to better in race toward very low values. Yet they lack inertia. When combined with other materials - or, even better, when a solid-to-liquid "phase-changing" material such as paraffin or a salt is added into the mixture - they (apparently) acquire the thermal inertia that they lack, by absorbing and reflecting latent heat of fusion. In spite of their remarkable performances, these insulating materials still lack the "breathability" of certain natural materials, related to the capacity for absorption, transfer and phasechange of water in vapor and liquid form - all properties which depend on the characteristics of the porous space of the material and the thermal and hydric coupling which manifests itself in that space.

\section{REFERENCES}

Amziane, L. Arnaud, Bio-aggregate-based Building Materials: Applications to Hemp Concretes, 2013, ISBN: $9781848214040,336 \mathrm{pp}$.

Arnaud, S. Amziane, V. Nozahic and E. Gourlay, Mechanical Behavior, in Bio-aggregate-based Building Materials: Applications to Hemp Concretes, 2013, ISBN: 9781848214040,Edited by, S. Amziane, L. Arnaud ,153-176 pp.

Arnaud, D. Samri and E. Gourlay, Hygrothermic behavior of hempcrete, 2013, ISBN: 9781848214040,Edited by, S. Amziane, L. Arnaud ,chapter 6.

Boutin and C. Flamin, Examination of the environmental characteristics of a banked hempcrete wall on a wooden skeleton, by life-cycle analysis: feedback on the LCA experiment from 2005, 2013, ISBN: 9781848214040,Edited by, S. Amziane, L. Arnaud ,chapter 9.

Escadeillas, C. Magniont, S. Amziane and V. Nozahic. Binders, in Bio-aggregate-based Building Materials: Applications to Hemp Concretes, 2013, ISBN: 9781848214040,Edited by, S. Amziane, L. Arnaud ,75-111 pp.

Glé, E. GOURDON and L. Arnaud., Acoustic properties of hempcretes , 2013, ISBN: 9781848214040,Edited by, S. Amziane, L. Arnaud chapter 7.

Lanos, f. Collet, g. Lenain and y. Hustache. Formulation and implementation, 2013, ISBN: 9781848214040,Edited by, S. Amziane, L. Arnaud, Chapter 2.

Munoz and D. Pipet, Plant-based concretes in structures: structural aspect - addition of a wooden support to absorb the strain, 2013, ISBN: 9781848214040 ,Edited by, S. Amziane, L. Arnaud, chap. 8. 
Nozahic, S. Amziane, Environmental, Economic and Social Context of Agro-Concretes,in Bio-aggregatebased Building Materials: Applications to Hemp Concretes, 2013, ISBN: 9781848214040,Edited by, S. Amziane, L. Arnaud , 1-25 pp.

Picandet, Characterization of granulates of plant origin, 2013, ISBN: 9781848214040,Edited by, S. Amziane, L. Arnaud ,Chapter 2. 